\title{
Quitting smoking in China: findings from the ITC China Survey
}

\author{
Yuan Jiang, ${ }^{1}$ Tara Elton-Marshall, ${ }^{2}$ Geoffrey T Fong, ${ }^{2,3}$ Qiang Li
}

${ }^{1}$ National Tobacco Control Office of the Chinese Center for Disease Control and Prevention, Beijing. China

${ }^{2}$ University of Waterloo, Waterloo, Canada

${ }^{3}$ Ontario Institute for Cancer Research, Toronto, Canada

\section{Correspondence to}

Tara Elton-Marshall, Department of Psychology, PAS Building, University of Waterloo, 200 University Avenue West, Waterloo, Ontario, Canada N2L 3G1; teelton@uwaterloo.ca

Received 30 April 2009 Accepted 14 December 2009

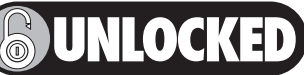

This paper is freely available online under the BMJ Journals unlocked scheme, see http:// tobaccocontrol.bmi.com/site/ about/unlocked.xhtml

\section{ABSTRACT}

Background Few studies have examined interest in quitting smoking and factors associated with quitting in mainland China.

Objective To characterise interest in quitting, quitting behaviour, the use of cessation methods and reasons for thinking about quitting among adult urban smokers in six cities in China.

Methods Data is from Wave 1 of the ITC China Survey, a face-to-face household survey of 4732 adult smokers randomly selected from six cities in China in 2006. Households were sampled using a stratified multistage design.

Findings The majority of smokers had no plan to quit smoking (75.6\%). Over half (52.7\%) of respondents had ever tried to quit smoking. Few respondents thought that they could successfully quit smoking (26.5\%). Smokers were aware of stop-smoking medications (73.5\%) but few had used these medications (5.6\%). Only 48.2\% had received advice from a physician to quit smoking. The number one reason for thinking about quitting smoking in the last 6 months was concern for personal health (55.0\%). Most smokers also believed that the government should do more to control smoking (75.2\%). Conclusion These findings demonstrate the need to: (1) increase awareness of the dangers of smoking; (2) provide cessation support for smokers; (3) have physicians encourage smokers to quit; (4) denormalise tobacco use so that smokers feel pressured to quit; (5) implement smoke-free laws to encourage quitting; (6) develop stronger warning labels about the specific dangers of smoking and provide resources for obtaining further cessation assistance; and (7) increase taxes and raise the price of cigarettes.

\section{INTRODUCTION}

China is facing a public health crisis with current smoking rates estimated at 320 million people. ${ }^{1}$ The majority of adult males (57\%), and 3\% of adult females in China are current smokers. ${ }^{2}$ Given these smoking rates, it is estimated that one million smokers in China die from tobacco-related illnesses each year ${ }^{1}$ and this number is expected to rise to 2.2 million deaths by $2020 .^{3}$ Smoking also poses an enormous health risk to non-smokers in China as it is estimated that $52 \%$ of non-smokers are exposed to tobacco smoke pollution for at least 15 minutes daily for more than 1 day every week. ${ }^{4}$

To reduce the health burden of smoking, smokers in China need to be prevented from smoking and encouraged to quit smoking. Recent studies have demonstrated that quitting even after many years of smoking can greatly reduce the risk of cancer, stroke and cardiovascular diseases. ${ }^{5} 6$ However, research conducted in 1996 and 2002 suggests that the majority of smokers in China $(71.8 \%$ and $74 \%$, respectively) have no intention of quitting smoking. ${ }^{47}$ Further studies examining intentions to quit smoking in China have not been conducted. It is unclear whether interest in quitting smoking has changed since this time.

The goal of this paper is to examine whether smokers in China are interested in quitting smoking, whether they have attempted to quit smoking and whether they have been successful. We will examine how smokers have attempted to quit smoking and whether smokers in China have received encouragement and support to successfully quit smoking. A recent study in China suggests that only $48 \%$ of physicians ask their patients about their smoking status and only $64 \%$ offer cessation advice to these smoking patients. ${ }^{8}$ Research evidence suggests that physicians' advice is a powerful motivator to encourage quitting. ${ }^{9-11}$ This study will therefore examine, from the smokers' perspective, whether smokers in China have received advice about quitting smoking from their physician or healthcare providers.

The use of other cessation methods that have proved to be effective will also be explored. For example, how many smokers in China have heard about and how many have used nicotine replacement therapy? Studies have demonstrated that this is one of the most effective cessation aids available. ${ }^{12}$ However, it is not known how common these medications are in China.

Another effective cessation strategy is the use of "quit and win" competitions to encourage smokers to quit. The Chinese International Quit and Win competition is currently one of the largest cessation activities in China. This strategy began in 1996 in Beijing, Shanghai and Tianjin. By 2006 the quit and win service had expanded to 31 provinces with approximately 130000 smokers participating. ${ }^{13} 14$ No studies to date have examined whether the majority of urban smokers in China are aware of the programme and how many have used this service.

Finally, this paper will explore smokers' reasons for thinking about quitting smoking. These reasons will provide important insights into which factors are salient to Chinese smokers and which policies/ programmes need to be strengthened in order to increase smokers' motivation to quit smoking.

\section{METHOD}

The following is a brief outline of the methods employed in the ITC China Survey. Additional detail is provided by $\mathrm{Wu}$ et $a l^{15}$ and in the ITC China Survey Wave 1 Technical Report, which can be found at http://www.itcproject.org. ${ }^{16}$ 


\section{Participants}

The ITC China Survey is a prospective cohort survey of 800 adult smokers and 200 adult non-smokers in each of six cities in China: Beijing, Shanghai, Guangzhou, Shenyang, Changsha and Yinchuan. A seventh city (Zhengzhou) was originally included in Wave 1 and Wave 2 of the ITC China Survey; however, the data from this city were later discarded after data quality testing suggested that the information was not reliable and therefore suspect. The overall sample size of the survey is 4800 for adult smokers and 1200 for adult non-smokers. This paper examines quitting behaviour of current smokers (defined as having smoked at least 100 cigarettes in a lifetime and currently smoking at least once a week). The Wave 1 survey was conducted in February-April 2006.

\section{Sampling design}

The six cities in the ITC China Survey do not constitute a random sample of the entire population of China. They were judiciously selected based on geographical representations and levels of economic development.

In each city, the ITC China Survey employed a multistage cluster sampling design. In each of the six cities, 10 street districts (Jie Dao) were randomly selected, with probability of selection proportional to the population size of the Jie Dao. Within each of these Jie Dao, two residential blocks (Ju Wei Hui) were selected, again with probability proportional to the population size of the Ju Wei Hui. Within each selected Ju Wei Hui, a complete list of addresses of the dwelling units (households) was first compiled, and then a sample of 300 households were drawn from the list by simple random sampling without replacement. In this way, the sampling frame was constructed in each city.

Information on age, gender and smoking status for all adults living in these 300 households was collected in the enumeration process. The enumerated 300 households were then randomly ordered, and adult smokers and non-smokers were then approached following the randomised order until 40 adult smokers and 10 adult non-smokers were surveyed. Because of low smoking prevalence among women, one male smoker and one female smoker from every selected household were surveyed whenever possible to increase the sample size for women. At most one non-smoker was interviewed per household. Where there was more than one person in a sampling category to choose from in a household, the next birthday method ${ }^{17}$ was used to select the individual to be interviewed.

A table demonstrating the sample characteristics for the Wave 1 respondents in this study can be found in the paper by EltonMarshall et al (this issue). ${ }^{18}$

\section{Procedure}

The enumerators and survey interviewers were organised and trained by the CDC staff in each city, with support and supervision from the ITC China team members both at the China National CDC and at the ITC Project Data Management Centre at the University of Waterloo.

The ITC China Survey was conducted through face-to-face interviews. The average time to complete a survey was 31.4 minutes for smokers (interquartile range around 10 minutes and 5 minutes). Interviewers followed a strict protocol in their interview session with each respondent. Up to four visits to a household were made in order to interview the target person(s) within that household.

All materials and procedures used in the ITC China Survey were reviewed and cleared for ethics by the research ethics board at the University of Waterloo and by the institutional review boards at the Chinese National Center for Disease Control and Prevention.

The Wave 1 cooperation rates were: $80.0 \%$ in Beijing (estimated), $80.0 \%$ in Guangzhou (estimated), $81.2 \%$ in Shenyang (exact), $84.2 \%$ in Shanghai (exact), $80.0 \%$ in Changsha (estimated) and $90.3 \%$ in Yinchuan (exact). The response rates range from $39.4 \%$ in Yinchuan to $66.0 \%$ in Guangzhou.

\section{Weight construction}

Sampling weights were constructed separately for male adult smokers, female adult smokers and adult non-smokers. Wave 1 weights were constructed by taking into account the four levels of sample selection: Jie Dao, Ju Wei Hui, household and individual. The final Wave 1 weight for a sampled individual was the number of people in the city population and the sampling category represented by that individual.

\section{Measures}

\section{Quitting behaviour and attitudes towards quitting}

Quit intentions were measured by asking respondents: "Are you planning to quit smoking?" (within the next month, within the next 6 months, sometime in the future beyond 6 months, not planning to quit/don't know). History of quitting was assessed by asking respondents whether they had ever tried to quit smoking (yes/no) and for those who had tried to quit smoking, the number of previous quit attempts $(1,2-5,6-10,>10)$. Selfefficacy was measured by asking respondents "how sure are you that you would succeed at quitting?" (not at all sure, somewhat sure, very sure, extremely sure).

To assess attitudes towards quitting smoking we asked: "how much do you think you would benefit from health and other gains if you were to quit smoking?" To determine whether smokers thought that the government should be more involved with tobacco control we asked whether respondents thought that: "the government should do more to control smoking".

\section{Awareness and use of cessation aids and services}

We assessed whether respondents were aware of smoking cessation aids, including stop smoking medications, Chinese traditional stop-smoking medications and stop-smoking acupuncture. We also asked respondents whether they had ever used stop-smoking medications. For those respondents who had used stop-smoking medications, we asked which medications they had used (nicotine gum, nicotine lozenges, nicotine nasal spray, Chinese traditional medicine, acupuncture, other).

To assess whether respondents had access to stop-smoking services, we asked those respondents who had visited a doctor or health professional in the last 6 months, whether they had received: Advice to quit smoking, additional help or referral to another service to help quit, a pamphlet or brochures on how to quit. In addition, we asked respondents whether they had received advice or information about quitting smoking in the last 6 months from: Telephone or quit line services, and local stop-smoking services (ie, hospitals or clinics). Finally, we asked respondents whether they were aware of the International Quit and Win contest in China.

\section{Reasons for thinking about quitting}

We asked respondents whether any of the following reasons had made them think about quitting in the last 6 months: Concern for personal health, concern about the effect of your cigarette smoke on non-smokers, China society disapproves of smoking, the price of cigarettes, smoking restrictions in public and work 
places, advertisements or information about the health risks of smoking, health warning labels on cigarette packages, setting an example for children, family disapproves of smoking. Response options were: not at all, a little, very much, don't know.

\section{Statistical analyses}

Weighted frequencies were conducted using Complex Samples in SPSS version 17.0.

\section{RESULTS}

Table 1 presents the weighted frequencies for quitting and attitudes towards quitting. The majority of smokers had no plan to quit smoking now or in the future $(75.6 \%)$. Over half $(52.7 \%)$ of respondents had ever tried to quit smoking and had attempted to quit 2-5 times (53.2\%). A minority of respondents felt that they could successfully quit smoking (26.5\% were 'very sure' or 'extremely sure'). There was some acknowledgement that the respondent would benefit from health and other gains if they were to quit smoking in the next 6 months $(35.1 \%$ said 'very much'). Most smokers also believed that the government should do more to control smoking (75.2\%).

Smokers in China were aware of stop-smoking medications (73.5\%) (table 2); however, less than half were aware of Chinese traditional stop-smoking medications (37.9\%) and stop-smoking acupuncture (27.6\%). Despite an awareness of stop-smoking

Table 1 Quitting behaviour and attitudes towards quitting

\begin{tabular}{|c|c|c|c|}
\hline & $\mathbf{n}$ & Weighted \% & $95 \% \mathrm{Cl}$ \\
\hline \multicolumn{4}{|l|}{ Quit intention } \\
\hline Within the next month & 377 & $8.0 \%$ & $7.0 \%$ to $9.0 \%$ \\
\hline Within the next 6 months & 297 & $6.7 \%$ & $5.3 \%$ to $8.5 \%$ \\
\hline $\begin{array}{l}\text { Sometime in the future beyond } \\
6 \text { months }\end{array}$ & 437 & $9.7 \%$ & $7.9 \%$ to $12.0 \%$ \\
\hline Not planning to quit/don't know & 3602 & $75.6 \%$ & $71.9 \%$ to $79.5 \%$ \\
\hline \multicolumn{4}{|l|}{ Ever tried to quit smoking? } \\
\hline Yes & 2512 & $52.7 \%$ & $50.7 \%$ to $54.7 \%$ \\
\hline No & 2219 & $47.3 \%$ & $45.2 \%$ to $49.3 \%$ \\
\hline \multicolumn{4}{|l|}{ Number of previous quit attempts } \\
\hline NA/Don't know/can't say & 45 & $1.8 \%$ & $1.2 \%$ to $3.0 \%$ \\
\hline 1 & 810 & $32.3 \%$ & $30.2 \%$ to $34.5 \%$ \\
\hline $2-5$ & 1368 & $53.2 \%$ & $50.2 \%$ to $56.1 \%$ \\
\hline $6-10$ & 151 & $6.8 \%$ & $5.0 \%$ to $9.1 \%$ \\
\hline$>10$ & 149 & $5.9 \%$ & $4.8 \%$ to $7.1 \%$ \\
\hline
\end{tabular}

How sure are you that you would succeed at quitting?

$\begin{array}{lrrl}\text { Don't know/can't say } & 334 & 6.5 \% & 5.4 \% \text { to } 7.9 \% \\ \text { Not at all sure } & 2004 & 42.9 \% & 40.3 \% \text { to } 45.5 \% \\ \text { Somewhat sure } & 1158 & 24.1 \% & 22.4 \% \text { to } 25.9 \% \\ \text { Very sure } & 622 & 13.9 \% & 12.1 \% \text { to } 15.9 \% \\ \text { Extremely sure } & 612 & 12.6 \% & 11.2 \% \text { to } 14.1 \%\end{array}$

How much do you think you would benefit from health and other gains if you were to quit smoking permanently in the next 6 months?

$\begin{array}{lrrr}\text { Not at all } & 944 & 19.4 \% & 17.6 \% \text { to } 21.4 \% \\ \text { A little } & 1532 & 32.0 \% & 29.1 \% \text { to } 35.1 \% \\ \text { Very much } & 1613 & 35.1 \% & 31.8 \% \text { to } 38.6 \%\end{array}$

Don't know/can't say $\quad 639 \quad 13.4 \% \quad 11.7 \%$ to $15.4 \%$

The government should do more to control smoking

$\begin{array}{lccc}\text { Strongly agree/agree } & 3539 & 75.2 \% & 69.9 \% \text { to } 80.9 \% \\ \begin{array}{l}\text { Strongly disagree/disagree/neutral/ } \\ \text { don't know }\end{array} & 1193 & 24.8 \% & 21.0 \% \text { to } 29.5 \%\end{array}$

Table 2 Awareness and use of cessation aids and services

\begin{tabular}{llll}
\hline & $\mathbf{n}$ & Weighted \% & $\mathbf{9 5 \%} \mathbf{C l}$ \\
\hline Aware of stop smoking medications & & & \\
$\quad$ Yes & 3509 & $73.5 \%$ & $71.1 \%$ to $75.9 \%$ \\
No & 1221 & $26.5 \%$ & $24.0 \%$ to $28.9 \%$
\end{tabular}

Aware of Chinese traditional stop-smoking medications

$\begin{array}{llll}\text { Yes } & 1830 & 37.9 \% & 35.7 \% \text { to } 40.0 \% \\ \text { No } & 2883 & 62.1 \% & 60.0 \% \text { to } 64.3 \%\end{array}$

Aware of stop-smoking acupuncture

Yes $\quad 1363 \quad 27.6 \% \quad 25.1 \%$ to $30.2 \%$

No $\quad 3354 \quad 72.4 \% \quad 69.8 \%$ to $74.9 \%$

Ever used stop-smoking medications?

$\begin{array}{lrrl}\text { Yes } & 274 & 5.6 \% & 4.8 \% \text { to } 6.6 \% \\ \text { No } & 4444 & 94.3 \% & 93.2 \% \text { to } 95.1 \% \\ \text { Cannot remember } & 8 & 0.1 \% & 0.1 \% \text { to } 0.4 \%\end{array}$

Among those who used cessation aids, ${ }^{*}$ medications/treatments ever used:

$\begin{array}{lrrl}\text { Nicotine gum } & 68 & 33.2 \% & 20.3 \% \text { to } 52.3 \% \\ \text { Nicotine lozenges } & 18 & 11.4 \% & 4.6 \% \text { to } 28.3 \% \\ \text { Nicotine nasal spray } & 21 & 15.3 \% & 6.4 \% \text { to } 35.1 \% \\ \text { Chinese traditional medicine } & 50 & 24.4 \% & 16.4 \% \text { to } 36.2 \% \\ \text { Acupuncture } & 15 & 10.1 \% & 3.8 \% \text { to } 25.4 \% \\ \text { Other } & 106 & 50.9 \% & 33.0 \% \text { to } 74.1 \%\end{array}$

Among those who visited a doctor or other health professional in the last 6 months, percentage who received:

\begin{tabular}{|c|c|c|c|}
\hline Advice to quit smoking & 583 & $48.2 \%$ & $45.0 \%$ to $51.4 \%$ \\
\hline $\begin{array}{l}\text { Additional help or referral to another } \\
\text { service to help quit }\end{array}$ & 51 & $4.3 \%$ & $2.9 \%$ to $6.3 \%$ \\
\hline Pamphlet or brochures on how to quit & 26 & $1.6 \%$ & $1.0 \%$ to $2.7 \%$ \\
\hline
\end{tabular}

Received advice or information about quitting smoking in the last 6 months from:

$\begin{array}{llll}\text { Telephone or quit line services } & 53 & 1.2 \% & 0.9 \% \text { to } 1.7 \%\end{array}$

Local stop-smoking services (ie, $\quad 389 \quad 8.4 \% \quad 7.4 \%$ to $9.6 \%$ hospitals or clinics)

Aware of the International Quit and Win contest in China

$\begin{array}{lrrl}\text { Yes } & 597 & 13.2 \% & 11.7 \% \text { to } 14.9 \% \\ \text { No } & 4117 & 86.8 \% & 85.1 \% \text { to } 88.3 \% \\ \text { Of those who were aware, \% } & 18 \dagger & 3.3 \% & 1.8 \% \text { to } 5.8 \%\end{array}$

participated

*Not every respondent who had ever used a cessation aid answered each question. There was some variability in the number of respondents who answered each question so the denominator for the percentage who used each could be different

$\dagger 47$ respondents who were aware of the International Quit and Win contest did not answer this question.

medications, few smokers in China had actually used these medications (5.6\%). Among those who had ever used stopsmoking medications, nicotine gum was the most popular (33.2\%).

The majority of smokers in China had not received any advice to help them quit smoking. Among those who visited a doctor or other healthcare professional in the last 6 months, only $48.2 \%$ had received advice to quit smoking. Almost no one had received additional help or a referral to another service to help quit (4.3\%). Smokers were also not given pamphlets or brochures on how to quit $(1.6 \%)$. In the last 6 months, most smokers $(1.2 \%)$ did not contact telephone or quit line services to get advice or information about quitting. Smokers were also unlikely (8.4\%) to have received advice or information to quit smoking from local stop-smoking services (ie, hospitals or clinics). In all, 13.2\% of the smokers were aware of the International Quit and Win 
contest in China, but only $3.3 \%$ had participated in this programme.

The number one reason for thinking about quitting smoking in the last 6 months was concern for personal health with $55.0 \%$ of respondents endorsing this belief (see table 3 ). The next most important reasons were: the impact of smoking on others, the effect of smoke on non-smokers (44.5\%), normative reasons, such as family disapproval $(42.0 \%)$ and concern for setting an example for children (40.5\%). A minority of respondents identified health information campaigns designed to deter smoking such as advertisements (28.3\%) and warning labels $(22.2 \%)$ as reasons to think about quitting. Smokers were least likely to say that price was a reason for thinking about quitting smoking in the last 6 months (21.8\%).

\section{DISCUSSION}

The majority of smokers in China do not intend to quit smoking (75.6\%). This finding is consistent with a 1996 national prevalence study and a 2002 study in which the majority of smokers had no intention of quitting. ${ }^{4}$ Clearly the smoking situation in China has not improved and may have even got worse. Over half of smokers had made one or more quit attempts but continue to smoke. It is possible that smokers are not able to quit successfully because cessation services and medications are not widely available in China. Alternatively, smokers may not feel pressured to remain smoke-free because they are not as concerned about the health effects of smoking. Indeed, few smokers reported that they would benefit from health or other gains if they were to quit. Increasing knowledge about the health effects of smoking could therefore increase interest in quitting and remaining smoke-free.

In addition to increasing public awareness about the risks of smoking, it is also important to increase smokers' confidence that they can quit smoking. ${ }^{19}$ These findings demonstrate that smokers lack the self-efficacy to be able to quit smoking. This may be due in part to a perceived lack of support in quitting.

One method that has been demonstrated to help smokers quit smoking is the use of stop-smoking medications. ${ }^{12}$ While smokers in China are aware of stop-smoking medications, few smokers have actually used them. Anecdotal evidence suggests that smokers are aware of these medications because of news stories about stop-smoking medications. Despite the fact that nicotine replacement therapy (NRT) does not require a prescription, few pharmacies actually sell these products and access is therefore limited. Additionally, as this study has demonstrated, few smokers in China are interested in quitting smoking and therefore wouldn't need to use these medications. Indeed, NRT has been available in China for about 10 years; however, there was little interest in this product and it was removed from the Chinese market. NRTwas later reintroduced to the market in 2007. Future research should explore the potential reasons why Chinese smokers are not interested in stop-smoking medications, and barriers to using these medications.

Awareness of Chinese traditional medicine to aid in smoking cessation was very low particularly compared to smoking cessation medications. Anecdotal evidence suggests that this is because there is little dissemination about the use of Chinese traditional medicine to aid in smoking cessation.

Physicians can provide smokers with the knowledge that smoking is harmful as well as assist smoker cessation. In fact, research in other countries has demonstrated that physicians' advice is an effective strategy to motivate smokers to quit.' However, this research demonstrates that physicians are not advising smokers to quit, providing smokers with information about how to quit (pamphlets/brochures) and referring smokers to other stop-smoking services to help them quit. The reason why physicians are not providing cessation advice may include a lack of cessation training in medical schools, and a lack of knowledge about the harmful effects of smoking. ${ }^{8}$ Future research could attempt to identify ways to encourage physicians to become more involved in encouraging smokers to quit.

Other cessation resources such as the Chinese International Quit and Win Campaign could also focus on educating smokers about the dangers of smoking while also providing support for quitting. This campaign was not well known among respondents in our survey, which therefore indicates that increased promotion of this service may increase smokers' participation. Telephone or quit services were also rarely used; however, this is not surprising given that these services were only available in Beijing in a limited scale at the time of our survey. Health information campaigns warning smokers about the dangers of smoking will soon be implemented in China in accordance with the Framework Convention on Tobacco Control (FCTC). Consequently, it is expected that more smokers in China will consider quitting smoking. It is therefore imperative that programmes to encourage smoking cessation are immediately developed and implemented in China to assist the anticipated increase in the number of health-concerned smokers.

The majority of smokers in China were not interested in quitting; however, it is important to examine which factors influence thinking about quitting. Understanding which factors are associated with thinking about quitting can inform how quitting campaigns should be targeted and which policies/ programmes need to be improved to encourage quitting.

The most popular reason for thinking about quitting smoking (in the next 6 months) was concern for personal health. This

Table 3 Reasons for thinking about quitting in the last 6 months

\begin{tabular}{|c|c|c|c|c|c|}
\hline Reason & Not at all & A little & Very much & Don't know & $\mathbf{n}$ \\
\hline Concern for personal health & $42.9 \%(40.3 \%$ to $45.5 \%)$ & $35.4 \%(33.1 \%$ to $37.8 \%)$ & $19.6 \%(17.8 \%$ to $21.5 \%)$ & $2.1 \%(1.4 \%$ to $3.1 \%)$ & 4723 \\
\hline $\begin{array}{l}\text { Concern about the effect of your cigarette } \\
\text { smoke on non-smokers }\end{array}$ & $52.8 \%(49.7 \%$ to $55.9 \%)$ & $32.7 \%(30.2 \%$ to $35.4 \%)$ & $11.8 \%(10.3 \%$ to $13.4 \%)$ & $2.7 \%(2.0 \%$ to $3.7 \%)$ & 4723 \\
\hline China society disapproves of smoking & $66.2 \%(63.3 \%$ to $69.0 \%)$ & $25.3 \%(22.9 \%$ to $27.9 \%)$ & $6.2 \%(5.2 \%$ to $7.3 \%)$ & $2.3 \%(1.6 \%$ to $3.2 \%)$ & 4723 \\
\hline The price of cigarettes & $76.7 \%(74.5 \%$ to $78.8 \%)$ & $17.2 \%(15.5 \%$ to $19.1 \%)$ & $4.6 \%(3.9 \%$ to $5.5 \%)$ & $1.5 \%(1.0 \%$ to $2.4 \%)$ & 4722 \\
\hline $\begin{array}{l}\text { Smoking restrictions in public and work } \\
\text { places }\end{array}$ & $56.3 \%(52.1 \%$ to $60.5 \%)$ & $30.9 \%(27.7 \%$ to $34.3 \%)$ & $9.8 \%(8.4 \%$ to $11.4 \%)$ & $2.9 \%(2.2 \%$ to $3.9 \%)$ & 4720 \\
\hline $\begin{array}{l}\text { Advertisements or information about the } \\
\text { health risks of smoking }\end{array}$ & $68.9 \%(65.5 \%$ to $72.1 \%)$ & $24.4 \%(21.5 \%$ to $27.5 \%)$ & $3.9 \%(3.1 \%$ to $4.9 \%)$ & $2.8 \%(2.1 \%$ to $3.8 \%)$ & 4723 \\
\hline $\begin{array}{l}\text { Health warning labels on cigarette } \\
\text { packages }\end{array}$ & $75.3 \%(72.6 \%$ to $77.7 \%)$ & $19.5 \%(17.3 \%$ to $22.0 \%)$ & $2.7 \%(2.1 \%$ to $3.4 \%)$ & $2.5 \%(1.9 \%$ to $3.4 \%)$ & 4722 \\
\hline Setting an example for children & $55.8 \%(52.4 \%$ to $59.1 \%)$ & $27.9 \%(25.6 \%$ to $30.4 \%)$ & $12.6 \%(11.0 \%$ to $14.4 \%)$ & $3.7 \%(2.9 \%$ to $4.8 \%)$ & 4722 \\
\hline Family disapproves of smoking & $55.7 \%(53.0 \%$ to $58.3 \%)$ & $28.7 \%(26.9 \%$ to $30.6 \%)$ & $13.3(11.6 \%$ to $15.1 \%)$ & $2.3 \%(1.7 \%$ to $3.1 \%)$ & 4721 \\
\hline
\end{tabular}


finding is consistent with a 1996 study demonstrating that $47 \%$ of smokers reported being sick as a reason to quit smoking and $34 \%$ reported that worrying about their health in the future was a reason to quit. ${ }^{7}$ Compared to other countries, however, endorsement of this belief was low in China (55.0\%) compared to respondents in our ITC South Korea project (80.5\%), for example. Again this suggests that further education about the health risks of smoking could increase the likelihood that Chinese smokers will quit smoking.

Concern for close friends and relatives seems to be another important motivator for smokers to quit. This is consistent with China as a collectivistic culture where, culturally, people in China tend to place more importance on the norms of their ingroup. ${ }^{20}$ If the norm is that you shouldn't smoke, the smoker would therefore feel more pressure to quit smoking. The finding also demonstrates that tobacco control policies in China could be improved to increase interest in quitting. Smoking restrictions, ${ }^{21}$ ads warning about the dangers of smoking, ${ }^{22}$ warning labels on cigarette packages ${ }^{23} 24$ and the price of cigarettes ${ }^{25}$ are all policies that have been effective in encouraging quitting in other countries. However, these policies are not listed as reasons to think about quitting smoking in China.

These findings are not surprising given that China does not have strong anti-smoking advertising. Few places in China are smokefree and warning labels are text-only with the vague message 'smoking harms your health'. The price of cigarettes in China is also very low; the cigarette tax rate in China is about $40 \%$ of the retail price (compared to $79 \%$ in Thailand, another developing country in Asia). The China Tobacco Monopoly actually subsidises tobacco factories for their production of less expensive cigarettes, which guarantees a supply of less expensive cigarettes.

\section{Implications}

Overall, these findings demonstrate the need to: (1) increase awareness of the dangers of smoking in China; (2) provide cessation support for smokers; (3) encourage physicians and other health professionals in China to become involved in encouraging and supporting smokers to quit; (4) denormalise tobacco use so that smokers feel increasing pressure to quit smoking particularly from close friends and family; (5) implement smoke-free laws to encourage quitting; (6) develop stronger warning labels about the specific dangers of smoking and provide resources for obtaining further cessation assistance;

\section{What this paper adds}

Few studies have examined interest in, and factors associated with quitting smoking among Chinese smokers. Those studies that have been conducted were completed 6 years or more ago. Therefore, it is important to examine up-to-date findings on whether: (1) smokers in China are interested in quitting; (2) whether smokers are accessing cessation support services and, if so, which services; (3) whether physicians and other healthcare professionals are encouraging smokers to quit; and (4) what factors are associated with thinking about quitting smoking in China. These findings will have implications for how tobacco control policies can be implemented in China to support and encourage smokers to quit smoking. It is imperative that China starts to implement effective cessation strategies because China currently has the highest smoking rate in the world and the potential loss of life if smokers continue to smoke is enormous.
(7) increase the price of cigarettes in China by increasing taxes on cigarettes.

Finally, some have argued that China is not ready for strong tobacco control policies. However, this study found that the majority of smokers agreed that the government should do more to control tobacco. Clearly it is time to implement stronger tobacco control policies that will encourage smokers to quit.

Acknowledgements The authors would like to acknowledge the Chinese Center for Disease Control and Prevention and the local CDC representatives in each city for their role in data collection.

Funding Chinese Center for Disease Control and Prevention, Canadian Institutes of Health Research, Canada (\#79551), National Cancer Institute (NCI)/National Institute of Health (NIH R01 CA125116-01A1), Roswell Park Transdisciplinary Tobacco Use Research Center (TTURC- P50 CA111236), funded by the U.S. National Cancer Institute, with additional support from a Canadian Institutes of Health Research Canada Graduate Scholarship Master's Award, a Canadian Institutes of Health Research Doctoral Research Award, and the Canadian Institutes of Health Research Strategic Training Program in Tobacco Research.

\section{Competing interests None.}

\section{Patient consent Obtained.}

Ethics approval Ethics approval was obtained from the Office of Research at the University of Waterloo (Waterloo Canada), and the internal review boards at: Roswell Park Cancer Institute (Buffalo, USA), the Cancer Council Victoria (Victoria, Australia) and the Chinese Center for Disease Control and Prevention National Center for AIDS/STD Control and Prevention (Beijing, China).

Provenance and peer review Not commissioned; externally peer reviewed.

\section{REFERENCES}

1. World Health Organization. Towards a tobacco-free China. Geneva, Switzerland World Health Organization, 2007. http://www.wpro.who.int/china/sites/tfi/ (accessed 15 Aug 2007).

2. World Health Organization. Report on the Global Tobacco Epidemic, 2008: the MPOWER package. Geneva, Switzerland: World Health Organization, 2008a. http:// www.who.int/tobacco/mpower/mpower report full 2008.pdf laccessed 20 Jun 2008).

3. Murray CJL, Lopez AD. Alternative projections of mortality and disability by cause 1990-2020: global burden of disease study. Lancet 1997;349:1498-504

4. Yang G, Ma J, Liu N, et al. Smoking and passive smoking in China, 2002. Chin J Epidemiol 2005;26:77-83.

5. Lam TH, Li ZB, Ho SY, et al. Smoking, quitting and mortality in an elderly cohort of 56,000 Hong Kong Chinese. Tob control 2007;16:182-9.

6. Godtfredsen NS, Lam TH, Hansel TT, et al. COPD-related morbidity and mortality after smoking cessation: status of the evidence. Eur Respir J 2008;32:844-53.

7. Yang G, Ma J, Chen A, et al. Smoking cessation in China: findings from the 1996 national prevalence survey. Tob Control 2001;10:170-4.

8. Yuan J, Ong MK, Tong EK, et al. Chinese physicians and their smoking knowledge, attitudes, and practices. Am J Prev Med 2007:33:15-22.

9. Stead LF, Bergson G, Lancaster T. Physician advice for smoking cessation. Cochrane Database Syst Rev 2008a;16(2):CD00165.

10. Schroeder SA. What to do with a patient who smokes. JAMA 2005;294:482-7.

11. Tobacco Use and Dependence Clinical Practice Guideline Panel, Staff, and Consortium Representatives. A clinical practice guideline for treating tobacco use and dependence: a US Public Health Service report. JAMA 2000;283:3244-54.

12. Stead LF, Perera R, Bullen C, et al. Nicotine replacement therapy for smoking cessation. Cochrane Database Syst Rev 2008b;1:CD000146.

13. Yang Y, Nan Y, Wei XS, et al. Analysis on 2004 China international quit $\&$ win and its follow-up survey after one month. Chin J Prev Control Chron NonCommun Dis 2005;13(2):54-56.

14. Zhu XM, Yang Y, Jiang Y, et al. The effect factors of 2004 Chinese quit and win and its sustaining developing policy. Chin J Prev Control Chron NonCommun Dis 2006;14 (1):53-54.

15. Wu C, Thompson ME, Fong GT, et al. Methods of the International Tobacco Contro (ITC) China Survey. Tob Control 2010:19:1-5.

16. International Tobacco Control China Survey Team. Wave 1 ITC China Technical Report. Waterloo, Canada, International Tobacco Control China Survey Team, 2008 http://www.itcproject.org/library/countries/itcchina/reports/finalitcch laccessed 17 Jun 2009).

17. Binson D, Canchola JA, Catania JA. Random selection in a national telephone survey: a comparison of the Kish, next-birthday, and last birthday methods. J Off Stat 2000;16:53-60.

18. Elton-Marshall T, Fong GT, Zanna MP, et al. Beliefs about the relative harm of "light" and "low tar" cigarettes: findings from the International Tobacco Control China survey. Tob Control 2010;19:54-62. 
19. Ockene JK, Emmons KM, Mermelstein RJ, et al. Relapse and maintenance issues for smoking cessation. Health Psychol 2000;19(Suppl 1):17-31.

20. Triandis HC. The self and social behavior in differing cultural contexts. Psychol Rev 1989:96:506-20.

21. Farkas AJ, Gilpin EA, Distefan JM, et al. The effects of household and workplace smoking restrictions on quitting behaviours. Tob Control 1999;8:261-5.

22. Hyland A, Wakefield M, Higbee $\mathrm{C}$, et al. Anti-tobacco television advertising and indicators of smoking cessation in adults: a cohort study. Health Educ Res 2006;21:296-302.
23. Borland $\mathbf{R}$, Yong $\mathrm{H}-\mathrm{H}$, Wilson $\mathrm{N}$, et al. How reactions to cigarette packet health warnings influence quitting: findings from the ITC four country survey. Addiction 2009; 104:669-75.

24. Hammond D, Fong GT, Borland R, et al. Text and graphic warnings on cigarette packages: findings from the International Tobacco Control Four Country Survey. Am J Prev Med 2007:32:202-9.

25. Innes M, Barling J, Rogers K, et al. De-marketing tobacco through price changes and consumer attempts to quit smoking. J Bus Ethics 2008;77:

405-16 